\title{
Grammaring, Its Effects on Oral Performance Among EFL Beginner-Level Learners in Higher Education
}

\author{
Erickzon D. Astorga Cabezas ${ }^{1,2}$ \& Paulina Bahamondes Beltran ${ }^{3}$ \\ ${ }^{1}$ EATRI Professional Institute, Providencia, Región Metropolitana, Chile \\ 2 Trewhela's School, Colina, Región Metropolitana, Chile \\ ${ }^{3}$ DuocUC Professional Institute, Santiago Centro, Región Metropolitana, Chile \\ Correspondence: Camino San José de Lo Pinto, Parcela 16, Colina, Región Metropolitana, Chile.
}

Received: August 7, 2021

Accepted: September 28, 2021

Online Published: September 29, 2021

doi: $10.5539 /$ elt.v14n10p130

URL: https://doi.org/10.5539/elt.v14n10p130

\begin{abstract}
Over several decades, numerous approaches applied to EFL have resulted in theories and reasonings to teach and learn English. Although Communicative Language Teaching (CLT) is the most commonly used path nowadays, it has only resulted in minimal development of university learners' oral skills; i.e., English-beginner-level students usually attain minimal scores on oral performance after instruction using CLT approaches in some Higher Education Institutions. Thus, this study aims to illustrate the impact of Grammaring approach, in combination with the practice of Form and Meaning as a complement to Use in CLT, on students' oral proficiency. Data from 38 students in control $(n=19)$ and experimental $(n=19)$ groups were analyzed. A descriptive and inferential statistical analysis of rubric bands from pre and post tests showed subtle improvements in aspects of Form (syntax) and Meaning (lexical use) but not in Use. These results have implications on what to teach and how to teach some language skills to lower-level learners, and highlights considerations for elaborating rubrics and assessing foreign language learners.
\end{abstract}

Keywords: grammaring, communicative language teaching, English as a foreign language, university first level of English, English teaching

\section{Introduction}

A significant number of universities are overtly adopting new instruction paradigms to aide their students develop specific abilities at the end of a course of study. This worldwide vision aligns to the development of measurable descriptions of professional knowledge, skills, behaviors and values among tertiary students required in the future (Guskey, 2005). This adoption known as Competency-based Education (CBE), implied obvious changes to, and renewal of, all curricula at a Chilean private university named Bernardo O'Higgins (UBO), especially in its English programs for different majors. Notably, UBO adopts Communicative Language Teaching because of its communicative point of view; a decision highly supported by Kibbe (2017) who posited that CLT had a more interactive and communicative point of view than other approaches centered on a structural position. Similarly, Richards \& Rodgers (2001) posited that CLT, apart from being focused on the widely-adopted Competency-based model in technical or professional education, is internationally recognized.

Thus, UBO had to intertwine the prevailing English Language Teaching approach (CLT) with CBE. Therefore, teaching English had to be centered on an instrumental purpose rather than the development of four skills namely speaking and writing. This change implied the adoption of principles from Competency-based Language Teaching (CBLT) exposed by Richards \& Rodgers (2001). An approach described as, 'CBLT as a method focused on what learners were expected to achieve with the target language' (p. 181) by Wong (2008), and Griffith \& Lim (2014) who stated that CBLT learning a foreign language facilitated developing excellent breadth and depth of knowledge in professions connected to a worldwide community. Therefore, we can say that relating CBE to CBLT illustrates how learners use their learned language skills to accomplish tasks associated with their professional development. Moreover, the adoption of new English teaching tendencies to a more communicative point of view promotes language dynamism and versatility in different contexts; a skill enhanced by Communicative Language Teaching (Nunan, 1989).

English teachers at UBO have been teaching using renown global approaches. However, the oral performance of their students in the language has been suboptimal. This phenomenon could be attributed to the fact that 
beginner-level EFL learners are not acquainted with the explicit lexical and grammatical structures as stated by Larsen-Freeman (2001), Brown (2004) and Longcope (2009). These researchers points of views are widely supported by their counterparts as such Cushing (2002) who stated that EFL learner should first learn grammar and vocabulary. Likewise, Melgajero (2009) expressed that among learners instructed in a foreign language, there is a tendency to trust lexical aspects more than semantic ones. Hence, CLT might not be a suitable approach for teaching English at a basic level in a foreign context. Nevertheless, the Grammaring Approach proposed by Larsen-Freeman (2001) presents a solution for beginner-level learners of oral English under the CBLT context. Larsen-Freeman's methodology links the dynamism of language by moving from rules to learning, and from lexis use to language production. This research study aims to illustrate the effects on adopting Grammaring on oral performance of beginner-level EFL learners at a specific pedagogical context.

\subsection{Problem Statement}

The main goal of this research was to show the possible effects of Grammaring on improving EFL beginner-level learners' oral proficiency in a specific pedagogical and institutional context.

The research general objective was be supported by the following specific objectives to focused on specific methodological and analysis considerations:

1) To identify which tri-dimensional bases of Grammaring are not yet shown by EFL beginner-level learners' oral proficiency at UBO.

2) To related the tri-dimensional principles of Grammaring to English teaching programs for beginner-level learners' oral proficiency at UBO.

3) To practically implement Grammaring at UBO in beginner-level learners' classes by emphasizing on least trained considerations of aforementioned approach.

\subsection{Research Rationale}

This study aims to illustrate the effects of Grammaring on EFL beginner-level learners' oral performance in the English language by operationalizing all the aforementioned authors' proposed considerations and complementing it with other scholars' theories and opinions. The primary suggestions related to CLT application propose avoiding explicit teaching, conversely, Grammaring promotes a more direct teaching approach. Investigators such as Nunan (1998), Thornbury (2001), Larsen-Freeman (2001), Brown (2004) and Longscope (2010) among many others propose feasible solutions to find a connection between prior dichotomy and probable relationships. This study therefore interlaced and verified some important topics into the fields of CLT, Speaking and Grammaring.

\section{Review of Literature}

Over the years, the use of English as a lingua franca has necessitated its' consideration as an essential part of people's professional development. Consequently, there is a global acclaim that high quality English language teaching and learning should take into consideration two main areas, namely the pedagogy and the context in which this language is taught.

\subsection{Speaking}

Speaking is one of the four prerequisite language skills for optimal language English performance as opposed to the other skills, viz, Listening, Reading and Writing (Bayu, 2015). Furthermore, Speaking is the default means of oral interaction among people. Additionally, oral production underpins the main objective of a second language syllabus for professional academic programs (Pan \& Pan, 2011). In other words, 'speaking should be mastered by students or people if they want to interact with other people around the world and get success later in their life' (Richard \& Renandya, 2002, p. 201).

Yet oral production development is usually linked to an individually performed and trained skills, and possibly also individually assessed skills (Norris, Davis, \& Timpe-Laughlin, 2017) in the EFL context, even at UBO, despite its' interactive nature.

It is essential to expand the overly simplified view of Speaking as something merely linguistic to clearly understand this skill. Oral speech production aims to provide oral messages recognized by speaker which are then processed and acknowledged by a receiver (Rickheit \& Strohner, 2008). Louma (2004) mentions that speaking implies possessing the micro and macro skills to master the sound system of the learned language, choose correct words, combine them in an appropriate order and avoid hesitation. Also, it is essential that a speaker adds aspects of comprehension from what her or she as a listener can perceive and in turn, to respond in real-time. Additionally, it is possible for a speaker to add linguistic and non-linguistic features such as cohesion, coherence and postures, gestures, nonverbal communication, etc., to his or her speech. Therefore, although 
speaking is routinely singly instructed and performed, its sub-skills suggest that this oral skill is usually noticeable during interactions between people.

As regards previous considerations, the adopting CLT into a more functional point of view implies the total exclusion of Form from language teaching and concentrating all teaching efforts on Use and if possible, on Meaning (Wu, 2008). Although renown linguists such as Stephen Krashen (1988) supported this fact, and N. S. Prabhu (1987) reinforced the ideas that Form, or better known as Grammar, is too difficult to teach, or are only taught unconsciously through exposure, there were other linguists who openly disagreed with them. For instance, Talley and Hui-Ling (1994) and Rao (2000) stated that the relationship between communicative strategies (implicit) and non-communicative activities (explicit) may widely benefit EFL learners from CLT.

\subsection{The Problems of Teaching Language in Forms (Grammar)}

Most teachers may consider some pros and cons when opting for methods or approaches to adopt when teaching the English language. Nevertheless, CLT has been the globally accepted form of instruction for foreign language learners.

The English language is divided into four skills, that are inter-related. When this language is taught under a communicative paradigm, the focus is on Form over Forms (Long, 1991); i.e., acquiring grammar rules through drawing learners' attention in activities, as opposed learning grammar in an explicit form, respectively.

The acquisition of a second language is thought to occur as the development of learners' communicative competence also occurs through communication and interaction with others (Brown, 2006; Mochida, 2002). The linguistic component proposed by (Canale, 1983), or the grammatical competence, was literally minimized to the field of 'learners' self-awareness'. However, this proposition has been proven unsuccessful for some EFL learners resulting in fossilization of language forms (Higgs and Clifford (1982); errors of addition and overuse of grammar (commission) and omission (Larsen-Freeman, 2003); lack of accuracy in learners' output (Williams, 1995) among many other failures.

On the one hand, there are many investigations that show the effect of restricting grammar into implicitness, on the other hand, other studies, such as the one by Lightbown (1998) and Wang (2009), prove the effectiveness of teaching grammar explicitly. However, these authors propose that grammar teaching should not focus on or ask learners to memorize rules, but should focus on the combination of form and communicative activities which are better known as structured input activities. In other words, these types of activities are centered on students' paying attention to the target language's grammatical forms through a meaningful context (Yin, C. \& Barrea-Marlys, M., 2012).

Although we may opt to teach English using structured input activities, some foreign contexts present additional dilemmas based on the place that grammar has in language curriculum and textbooks.

Swan (2011) mentioned that the curriculum in foreign language teaching focuses on, 'skills and strategies can receive more attention in teaching programmes than grammar, pronunciation and vocabulary' ( $\mathrm{p}$. 567). As regards English language tests, Hinkel (2017) concluded that because of the evidence found in research studies conducted by language testing institutions such as the Educational Testing Service (ETS) and the University of Cambridge Local Examination Syndicate (UCLES), 'the importance of grammar among L2 production skills cannot be underestimated' (p. 371).

Hinkel exemplified this underestimation by showing that the current language tests administered by the aforementioned institutions tended to majorly focus on grammar when testing students' productive skills (Speaking and Writing). Evidently, both the curriculum and assessments are centered more on Forms than Form.

Furthermore, there has been some criticism towards how context is set when teaching grammar using certain materials such as textbooks. For instance, Batstone and Ellis (2009, p. 195) claim that,

'Language teaching textbooks frequently introduce new grammatical items and their meanings through setting up a context of some sort in order to establish the appropriate meaning. Superficially, at least, these contexts set the scene for subsequent explicit explanation and practice of the grammatical form. However, it is much less common for textbooks to provide clear principles for guiding learners from the former (the meaning) to the latter (the form).'

Moreover, as regards the lesson structure, Larsen-Freeman states that 'in the past the practice stage of a language lesson had to do with grammar drills and exercises, which fail to provide 'meaningful practice' (2001, p. 258). Larsen-Freeman then stipulates that using these drills learners, develop 'inert knowledge' which cannot be used when a learner has to communicate spontaneously during interactions with others. 


\subsection{The Emergence of Grammaring}

Speaking cannot be taught and learned as a single skill, but as a combination of micro skills composed of phonology, morphology, syntax and pronunciation (visible and audible units). Additionally, it also has to do with all aspects related to meaning such as aspect, vocabulary, and how speaker and listener contextualize messages they use. (Larsen-Freeman, 2003)

Apart from the problems of misunderstanding of Speaking as skills, Grammar has been seen considering different perspectives. Some researchers such as Celce- Murcia (1991), Brown (1994), Larsen-Freeman (2001), are in agreement about the benefits of grammar teaching, but other researchers such as Krashen (1988) believe that learning and teaching grammar do not have an impact on acquiring a foreign language. However, grammar can be taught in a more interactive and meaningful context. Hence, knowing grammar alone essential to avoid fossilization to perform effective communicative interaction but is not sufficient for effective communication it is.

In the literature, there is a scholar who has established a theory that combines two points of view to provide a more suitable term of grammar in language teaching and learning; instructing grammar as knowledge and practice.

Diane Larsen-Freeman coined the term Grammaring, which is described as, 'the ability to use grammar constructions accurately, meaningfully, and appropriately.' (Larsen-Freeman, 2014, p. 264). Additionally, she stressed that Grammaring has an active nature with the 'ing' suffix reflecting this condition.

Therefore, since grammar is seen as a skill to be developed, classifying Grammaring into language teaching and learning theories implies an ability to follow the steps of Skill-Theory-Based Instruction as identified by Ur (2011).

In fact, Larsen Freeman (2001, p. 255) points out

'By thinking of grammar as a skill to be mastered, rather than a set of rules to be memorized, we will be helping ESL/EFL students go a long way toward the goal of being able to accurately convey meaning in the manner they deem appropriate.'

There are three dimensions of Grammaring and each dimension has a set of prototypical units (Larsen freeman, 2003). The first dimension is Form which embraces sounds or phonemes, written symbols, inflectional morphemes, function words and syntactic structures or grammatical issues.

Then, the second dimension is Meaning which has to do with Semantics including the prototypical units of lexemes, derivational morphemes, multiword lexical strings and notions. Lastly, the third dimension is Use, which is related to Pragmatics, deals with social functions as speech acts and discourse patterns.

Therefore, if a teacher decided to develop Grammaring in his/her students, he/she would have to design or find activities that individually or collectively activate the three dimensions of Form, Meaning and Use (as the activities described in 4.2.3).

\section{Methodological Framework}

In previous chapters, we stated all the theoretical, explanatory and practical concerns of Speaking, grammar and Grammaring to fulfill our general and specific objectives, and to provide guidelines for the selection of participants, materials, procedures and methods for analysis of results.

For this research, a quantitative approach was employed to illustrate how a specific methodology works in a specific context, and to provide abroad view of how possible performances influence outcomes. Hence, all these considerations directed us to follow a Postpositivist Paradigm (Creswell, 2009).

\subsection{Participants}

The next step in our investigation was to choose our study participants. The total number of students was 38 . All students were divided into a control group of 19 students and an experimental group of 19 students. Nevertheless, this was a convenient sample since participant selection was dependent upon the availability of courses and the number of students in these classes.

\subsection{Instruments}

Quantitative data was collected by administering pre- and post- oral tests, which were then reviewed using a specifically designed rubric. Theoretical and practical concerns from Brown (2004) were used to check the validity and reliability process of our assessment procedures. 


\subsubsection{Pre-Test and Post-Test Design and Application}

An oral test was designed to serve a double purpose. Firstly, as a pre-test to identify the participants' strengths and weaknesses regarding Grammaring under a specific content, Present Simple, to help determine what aspects of Grammaring should be taught first and subsequently in our context. Secondly, the test served as a post-test to register the performance of the control and experimental groups. Finally, the rubric was used in pre- and post-test procedures to collect data on participants' performances. The test and rubric were adapted from the format of the speaking component of two English language international exams such as Key English Test (KET) (UCLES, 2007) and Preliminary English Test (PET) (UCLES, 2016). We only used the format of some sections of these exams because these tests use of prompts and images to facilitate interaction between two participants. Furthermore, these types of tests are suitable- with some modifications - for EFL learners undergoing instruction using the Grammaring approach.

The oral test and rubric were organized into six sections that are described subsequently. The pre- and post-tests were carried out in student-pairs. If a participant did not have a partner, the examiner played the role of the participant's partner from the second to the sixth sections.

In the first section, participants were asked general questions in the Present Simple tense akin to the first section of the speaking paper of KET. There were three questions on familiar topics, ranging from basic personal information to everyday activities. The main focus of this section was to test participants' question comprehension, appropriateness of their answers, lexical use and negotiation.

In the second part of the test, each participant was given a card with some information about a celebrity (name, age and country). The researcher then posed some questions to each participant to assess their comprehension and the appropriateness of their answers.

In the third section, students were asked to role-play based on information on a card issued to them. This activity was likened to a jigsaw puzzle since both participants received prompts to pose questions and some specific answers they should use for those prompts provided that the questions are properly performed. This activity assessed question formation, intonation, function and negotiation.

In the fourth part of the test, participants were asked to construct sentences by conjugating the verbs in third person singular after receiving information on three everyday actions. This section measured participants' ability to describe routines in the third person singular in its appropriate conjugation in the present simple tense.

In the fifth section, each participant was asked to describe a celebrity's routine by stating what he/she does or does not do after receiving a sheet with illustrations. The aim of this activity was to assess lexical use, syntax and morphology.

Finally, the sixth section set out to facilitate interaction between two participants by providing prompts to each participant to pose questions to the other participant which would subsequently be answered. This task helped to comprehensively assess form, meaning and use.

\subsubsection{Rubric}

According to Pan and Pan (2011), there are Holistic Scoring and Analytic Scoring procedures. However, based on our research purpose, we opted for the latter type of rubric as its' scales provide more specific details in each component of any communicative competence (Jones, 1996), and they could also be linked to those used in international exams (see UCLES, 2007). Therefore, we designed a rubric to evaluate participants' performance in the pre and post-tests according to the three dimensions of Grammaring (Form, Meaning and Use). The rubric was written in Spanish for ease of comprehension of the assessors who were non-native English speakers whose first language was Spanish. The three dimensions of Grammaring, described as macro criteria with respect to the production of Present Simple, were divided into micro criteria. For example, the first macro criterion Form was divided into three micro criteria: pronunciation (production of intelligible segmental and suprasegmental sounds), syntax (correct order of affirmations, negations and questions) and morphology (correct formation of words and conjugation in present simple). The second macro criterion was Meaning, was divided into aspect (adequate recognition of the verbal tense in which interaction takes place) and lexical use (varied and accurate vocabulary according to the audience and topic, plus the meaning of the concept is connected to the sentence appropriately).

The third macro criterion, Use, was comprised of functions (recognizing intention and context); negotiation (delivery of the oral message through conversational resources such as elicitation, reiteration); and discourse (cohesion of the oral text through the use of subject pronouns and the use of simple connectors).

The score in each evaluation criterion ranged from 0 (total absence) to 4 (adequate performance). 


\subsubsection{Grammaring Activities}

A set of activities was selected to develop learners' speaking skills through Grammaring. Most of these activities were part of our own teaching knowledge and practices, whereas others were drawn from material resources of famous English language teaching textbooks. Students participated in these activities in class for three months (September-November).

a) Miming sentences: this activity stimulated practicing Form (mainly syntax and morphology) and Meaning (mainly lexical use). Firstly, the researcher demonstrated certain gestures to represent pronouns, verbs and vocabulary. In groups, one participant took a slip with a sentence in the present simple tense and used mimicry to represent each word in it, while the rest of the participants in the group attempted to guess what the sentence was about.

b) Surveys: each participant was given a sheet of paper with scrambled questions to order and pose them to other classmates so as to elicit information. This activity aimed to improve pronunciation, especially intonation; syntax for question formation; aspect and negotiation.

c) Information-gap activities: the focus of these activities was mainly on Meaning and Use. In pairs, participants were given cards or sheets with missing information and had to ask each other to complete the profile of a character. This type of activity activated syntax, morphology, pronunciation, negotiation and discourse.

d) Role-playing: In some lessons, participants in pairs, were given a card with specific information. For example, to fill a form to enroll in a course on the phone or in an office, one participant played the role of a secretary and while the other acted as the potential student. Questions were posed to the student about his/her name, age, nationality, occupation, hobbies, and so on. This activity aimed at developing the macro criterion of use, especially functions, negotiations and discourse.

e) Yes/no questions in present simple tense to guess identities: In a group of four, each participant took a slip with the name of a well-known celebrity among the participants' age group (15-25) and placed the slip on his/her forehead without looking at the celebrity's name. The participant then asked yes/no questions to his/her group to enable him/her identify the celebrity.

f) Replacing drawings with words: This activity was focused on developing lexical use by associating an illustration with its correct name. We used activities from some English language textbooks that had neat illustrations aligned with the content already addressed in class.

g) Matching questions and answers: This activity was mainly focused on the macro criterion of Use. In pairs, each participant was given a list of questions in the present simple tense and his/her partner also received a list of answers and together they would match the appropriate question to the appropriate answer.

\section{Results and Discussion}

The main aim of this study was to show the possible effects of Grammaring on improving EFL beginner-level learners' oral proficiency in a specific pedagogical context by taking into account how specific micro criteria may influence their ultimate performance. In this chapter, we present and discuss the results of our main and specific research questions. All rubric' criteria were subject to central and dispersion tendencies to comprehensively assess the effects of Grammaring on oral performance.

We used the mode, median, mean scores to summarize the data distribution. The mode was used to show the most frequent score in terms of performance level in each sub-dimension. It is important to mention that the highest score in this statistical measure will indicate what it is the current level of each EFL beginner-level learner in the corresponding sub-dimension.

The median was used to provide a better interpretation of the standard deviation since the Mean is susceptible to the influence of outliers.

Finally, we used the standard deviation to indicate how close or far performance levels were from the mean. i.e., values below 0.99 showed no improvements in terms of sub-division of dimensions; whereas, values above 0.99 would express improvements related to sub-division of dimensions. Additionally, a t-test was applied to assess the mean differences between the pre- and post-test scores.

Additionally, these inferential statistics complemented our descriptive statistics. 


\subsection{Statistical Analysis}

\subsubsection{Descriptive Statistical Analysis on FORM}

Table 1. Pronunciation analysis

\begin{tabular}{lllll}
\hline \multirow{2}{*}{$\begin{array}{l}\text { Group } \\
\text { Assessment Procedures }\end{array}$} & Pre-test & Post-test & Pre-test & Post-test \\
Variable & & & & \\
\hline Mo & $1-2$ & 2 & 2 & 2 \\
Me & 2 & 2 & 2 & 2 \\
$\overline{\mathrm{x}}$ & 2.0 & 2.2 & 2.3 & 2.1 \\
$\sigma$ & 0.95 & 0.88 & 0.84 & 0.85 \\
\hline
\end{tabular}

Key: Mo (Mode); Me (Median); $\bar{x}$ (Mean) and $\sigma$ (Standard Deviation)

The Control Group had minimal progress - $\mathbf{8 4}$ to $\mathbf{8 5}$ - in their pronunciation, i.e., in the way words are spoken after English studying for a whole semester. Similar results were observed with the Experimental group whose standard deviation decreased - $\mathbf{. 9 5}$ to $\mathbf{. 8 8}$-.

Table 2. Syntax Analysis

\begin{tabular}{llllc}
\hline Group & \multicolumn{3}{l}{ Experimental Group $(\mathrm{n}=19)$} & \multicolumn{2}{l}{ Control Group $(\mathrm{n}=19)$} \\
$\begin{array}{l}\text { Assessment Procedures } \\
\text { Variable }\end{array}$ & Pre-test & Post-test & Pre-test & Post-test \\
\hline Mo & 1 & $1-2$ & 2 & \\
$\mathrm{Me}$ & 2 & 2 & 2 & 2 \\
$\overline{\mathrm{x}}$ & 1.8 & 2.4 & 2.2 & 1.75 \\
$\sigma$ & 0.92 & 1.12 & 0.90 & 0.85 \\
\hline
\end{tabular}

Key: Mo (Mode); Me (Median); $\bar{x}$ (Mean) and $\sigma$ (Standard Deviation)

The Control group did not improve how they organized the elements or structures of the sentence, i.e., their word order. Additionally, the control group had lower median and mean in post-tests values portraying a negative progress in this sub-dimension (median: 2 to 1.75; mean: 2.2 to 1.8). For experimental group, there were mean higher values (1.8 to 2.4 ), but unchanged median values ( 2 to 2 ).

Thus, there is a slight improvement in syntax under a Grammaring teaching context based on a change in standard deviation from $\mathbf{. 9 2}$ to $\mathbf{1 . 1 2}$.

Table 3. Morphology Analysis

\begin{tabular}{lllll}
\hline Group & \multicolumn{3}{l}{ Experimental Group $(\mathrm{n}=19)$} & \multicolumn{2}{l}{ Control Group $(\mathrm{n}=19)$} \\
Assessment Procedures & Pre-test & Post-test & Pre-test & Post-test \\
Variable & & & & \\
\hline Mo & 1 & 1 & $1-2$ & 2 \\
$\mathrm{Me}$ & 2 & 2 & 1.75 & 1.75 \\
$\overline{\mathrm{x}}$ & 1.8 & 2.1 & 2.0 & 1.8 \\
$\sigma$ & 0.96 & 1.01 & 0.83 & 0.82 \\
\hline
\end{tabular}

Key: Mo (Mode); Me (Median); $\bar{x}$ (Mean) and $\sigma$ (Standard Deviation)

As seen in the results on Syntax, the Control group went from higher values to lower ones on assessments regarding the form, i.e., learners organizing the structures of words and parts of the words -stems, root, prefixes and suffixes- in context. Conversely, experimental group showed minimal some improvement in mean, that changed from .96 to 1.01 . 


\subsubsection{Descriptive Statistical Analysis on MEANING}

Table 4. Aspect Analysis

\begin{tabular}{|c|c|c|c|c|}
\hline \multirow{2}{*}{$\begin{array}{l}\text { Group } \\
\text { Assessment Procedures }\end{array}$} & \multicolumn{2}{|c|}{ Experimental Group $(\mathrm{n}=19)$} & \multicolumn{2}{|c|}{ Control Group $(\mathrm{n}=19)$} \\
\hline & Pre-test & Post-test & Pre-test & Post-test \\
\hline \multicolumn{5}{|l|}{ Variable } \\
\hline Mo & $1-2$ & $1--2$ & $2-3$ & 2 \\
\hline $\mathrm{Me}$ & 2 & 2 & 2 & 2 \\
\hline$\overline{\mathrm{x}}$ & 1.9 & 2.3 & 2.0 & 2.0 \\
\hline$\sigma$ & 0.90 & 1.15 & 0.85 & 0.82 \\
\hline
\end{tabular}

Key: Mo (Mode); Me (Median); $\overline{\mathrm{x}}$ (Mean) and $\sigma$ (Standard Deviation)

Table 5. Lexical Use Analysis

\begin{tabular}{llclc}
\hline Group & \multicolumn{2}{l}{ Experimental Group $(\mathrm{n}=19)$} & \multicolumn{2}{c}{ Control Group $(\mathrm{n}=19)$} \\
Assessment Procedures & Pre-test & Post-test & Pre-test & Post-test \\
Variable & & & & \\
\hline Mo & 1 & $1-2$ & 2 & 2 \\
Me & 2 & 2 & 2.5 & 2 \\
$\overline{\mathrm{x}}$ & 1.7 & 2.3 & 2.3 & 1.8 \\
$\sigma$ & 0.92 & 1.17 & 0.83 & 0.82 \\
\hline
\end{tabular}

Key: Mo (Mode); Me (Median); $\bar{x}$ (Mean) and $\sigma$ (Standard Deviation)

For both sub-dimensions (i.e., Aspect and Lexical use analysis), there were no important changes in scores of the Control Group. For Aspect, or the identification the appropriate tense and corresponding infection in relation to the expressed oral message in context, there was no progress among learners in the control group .85 to .82 . However, when assessing the appropriate use of vocabulary in context, there was evidence of some slight improvement, but not sufficient to advance to another level of performance (.92 to 1.17). In other words, with the Experimental group, we saw higher values in mean for both Aspect (1.9 to 2.3) and Lexical Use (1.7 to 2.3) in the posttest when compared to the pretest. These increasing values were also reflected in the corresponding deviation standard values (.90 to 1.15 for Aspect and $\mathbf{. 9 2}$ to 1.17 for Lexical Use) with more changes seen in Lexical Use when compared to Aspect.

\subsubsection{Descriptive statistical analysis on USE}

Table 6. Negotiation Analysis

\begin{tabular}{llllc}
\hline Group & \multicolumn{2}{l}{ Experimental Group $(\mathrm{n}=19)$} & \multicolumn{2}{l}{ Control Group $(\mathrm{n}=19)$} \\
Assessment Procedures & Pre-test & Post-test & Pre-test & Post-test \\
Variable & & & & \\
\hline Mo & 1 & 1 & 1 & 1 \\
$\mathrm{Me}$ & 1.75 & 1.75 & 2 & 1 \\
$\overline{\mathrm{x}}$ & 1.8 & 1.8 & 1.9 & 1.5 \\
$\sigma$ & 1.13 & 1.27 & 0.92 & 1.11 \\
\hline
\end{tabular}

Key: Mo (Mode); Me (Median); $\bar{x}$ (Mean) and $\sigma$ (Standard Deviation)

For Negotiation, or delivery of oral messages resorting to conversational resources, showing clear patterns of interaction in terms of questions/answer process, there was almost an imperceptible progression. Although, the standard deviation showed higher results in post-tests (.92 to 1.11), the mean values decreased from 1.9 to 1.5 . This variation will be explained subsequently. Regarding the Experimental Group, although the mean remain 
unchanged, there were changes in the Standard Deviation (1.13 to $\mathbf{1 . 2 7})$ with only value of performance level scores of $\mathbf{1}$. In other words, there was almost no significant progression when compared to the control group's results because the progress was within the level of performance.

Table 7. Functions Analysis

\begin{tabular}{|c|c|c|c|c|}
\hline \multirow{2}{*}{$\begin{array}{l}\text { Group } \\
\text { Assessment Procedures }\end{array}$} & \multicolumn{2}{|c|}{ Experimental Group $(\mathrm{n}=19)$} & \multicolumn{2}{|c|}{ Control Group $(\mathrm{n}=19)$} \\
\hline & Pre-test & Post-test & Pre-test & Post-test \\
\hline \multicolumn{5}{|l|}{ Variable } \\
\hline Mo & 2 & 1 & 2 & $1-2$ \\
\hline $\mathrm{Me}$ & 2 & 2 & 2 & 2 \\
\hline$\overline{\mathrm{x}}$ & 2.0 & 2.3 & 2.1 & 1.9 \\
\hline$\sigma$ & 1.01 & 1.22 & 1.04 & 0.93 \\
\hline
\end{tabular}

Key: Mo (Mode); Me (Median); $\bar{x}$ (Mean) and $\sigma$ (Standard Deviation)

Functions (the recognition of communicative context (affirmative, negative and interrogative structures) in terms of oral exchanges related to the topic and the ways to interact in conversation) showed a slight regression in Mode, Mean and Standard Deviation.

The learners' results were lower in the post-tests than in the pre-tests for the Control Group. Similar to Negotiation, the Experimental Group progressed but remained at the same level of performance (pre-test 2 to post-test 1) implying no improvement in performance level's values in this sub-dimension.

Table 8. Discourse Analysis

\begin{tabular}{lllll}
\hline Group & \multicolumn{2}{l}{ Experimental Group $(\mathrm{n}=19)$} & \multicolumn{2}{c}{ Control Group $(\mathrm{n}=19)$} \\
Assessment Procedures & Pre-test & Post-test & Pre-test & Post-test \\
Variable & & & & \\
\hline Mo & 1 & 1 & 1 & $1-2$ \\
$\mathrm{Me}$ & 1.25 & 2 & 2 & 1 \\
$\overline{\mathrm{x}}$ & 1.8 & 1.9 & 1.7 & 1.7 \\
$\sigma$ & 1.19 & 1.29 & 1.06 & 1.16 \\
\hline
\end{tabular}

Key: Mo (Mode); Me (Median); $\bar{x}$ (Mean) and $\sigma$ (Standard Deviation)

There were comparable results in terms of cohesion through textual structures such as anaphora or cataphora or basic connectors for both groups. Both groups had evident progression in Mean and Standard Deviation. However, the Modal score for each group was 1. Thus, improvements were seen at the same level of competence without competencies' advancements in this sub-dimension.

Several interpretations could be made from the tables above. It is important to note that students only need to be ranked at level 2 of performance to fulfill the minimum requirements for approval for each sub-dimension.

Generally, EFL learners at UBO were ranked at level 2 (Mode) of performance in terms of FORM and MEANING. i.e., they only attained minimal scores in their English oral production related to grammar and semantics. The corresponding scores for these EFL learners in USE or pragmatics would be level 1 of performance).

As researchers, we describe learners' performance as progression when the MODE, MEAN and STANDARD DEVIATION are higher results in the post-tests than in the pre-tests both Experimental and Control groups. A higher Mean implies that students are achieving better results and scoring above the Median or Mean. Additionally, when the Standard Deviation exceeds 0.99, the students are performing better in English in relation to its' sub-dimensions, i.e., they are moving from performance levels 1 to 2 , or 2 to 3 , or 3 to 4 . The exception to these considerations is Pronunciation in FORM where Median is used to avoid results from outliers (the Median results in pronunciation were 2 in the pre-test and 2 in the post-test). The Mean changed from 2.0 to 2.2 because some EFL learners may have had drastic increases in scores from $\mathbf{1}$ in pre-test ton $\mathbf{4}$ in the post-test, or from $\mathbf{2}$ in the pre-test to 4 in the post-test. As a consequence, there were increases in the Mean in pronunciation due to 
outliers. However, there was a decrease in the Standard Deviation from - $\mathbf{9 5}$ to $\mathbf{. 8 8}$ - similar to the Meanbecause some students may have had similar drastic decreases in scores from $\mathbf{3}$ in the pre-test to $\mathbf{1}$ in the post-test, or from $\mathbf{4}$ in the pre-test to $\mathbf{2}$ or $\mathbf{1}$ in the post-test. The dispersion was mainly concentrated closer to the Mean or the Median.

In other words, EFL learners improved as whole group in terms of Syntax and Morphology because the dispersion in scores was more concentrated on good and higher results. However, they regressed in Pronunciation because their level of performance was too low or closer to the Median or Mean. i.e., there were more individual variations among these EFL learners.

As regards the dimension of USE and its sub-dimensions, there was no progressions in either group. First of all, each sub-dimension, such as Negotiation, Functions and Discourse, was ranked at level 1 (Mode) for both groups. Therefore, EFL learners did not enhance their performance in aspects of pragmatics.

Similarly, the Mean was similar in the corresponding Pre and Post tests for Discourse (Control group: 1.7 for pre and post; Experimental group: 1.8/1.9 for pre and post) implying no progression in this sub-dimension. Although the Control Group had higher values (1.06 to 1.16) than the Experimental group (1.19 to 1.29), this dispersion occurred at the same level of performance (i.e., $\mathbf{1}$ or $\mathbf{2}$ ).

The control group had lower scores in Negotiation and Functions in the post-tests, i.e., 1.9 to $\mathbf{1 . 5}$ and $\mathbf{2 . 1}$ to 1.9, respectively. In this dimension, it was possible to see the phenomenon of varied outliers. Some EFL learners had much lower scores in post-tests than in the pre-tests; for instance, changes from $\mathbf{3}$ or $\mathbf{4}$ to $\mathbf{1}$ or $\mathbf{0}$. Consequently, the overall performance level considerably decreased. For the Experimental Group, there were no changes to the Negotiation scores (1.8), while Functions' scores changed from 2.0 to 2.3. In other words, we may say that some EFL beginner-level learners scored $\mathbf{3}$ or $\mathbf{4}$ after having scores of $\mathbf{0}$ or $\mathbf{1}$. If we analyze the Standard Deviation of Functions and Negotiation sub-dimensions for the Experimental Group, there was progression at the same level of performance; from 1.01 to 1.22 for Functions and from 1.13 to 1.27 for Negotiation. In other words, there was an improvement among only specific individuals and in relation to only specific issues in each sub-dimension.

In summary, changes in Standard Deviation from to lower to higher values does not necessarily imply improvements in oral performance. This is because we have to understand what the scores accorded to each level of performance $(0,1,2,3$ and 4$)$ represent in terms of mastering in each Grammar sub-dimension. For instance, moving from .90 to 1.15 in Morphology among students from the Experimental Group may be interpreted as mastering the aspects of using s/es in the third person in the Present Simple. However, moving from $\mathbf{1 . 0 1}$ to 1.22 in Functions among the same students may be understood as slightly mastering an aspect of the whole sub-dimension. For example, if student 1 asks, "Do you like sports?" and student 2 answers, "Yes". It is evident that student 2 understands the short question and knows how to respond to it, but he/she has not yet mastered the complement of the answer. Therefore, this answer would be partially correct. Thus, the identification of a significant progression or an impact of Grammaring on oral development among EFL beginner-level learners will depend on specific higher values in Mean scores and their Standard Deviation complemented by Modal and Median scores.

In support of our prior discussion, some progression was seen in Form and Meaning; however, it is not clear if this improvement was statistically significant.

\subsubsection{Inferential Statistical Analysis on FORM - MEANING and USE}

The post-tests' results from the Control and Experimental groups were used to calculate the t-test to assess whether or not there were significant improvements in oral performances between two time periods. It was assumed that figures were distributed in $\alpha=.05$. Therefore, our hypotheses about the Grammaring treatment were:

Null hypothesis: Applying Grammaring does not lead to improvements in oral performances.

Alternative hypothesis: Applying Grammaring leads to improvements in oral performances.

Therefore, our formula was $\mathrm{t}(\mathrm{x})=0.00, \mathrm{p}($ Value $)<.05$ 
Table 9. T-test applied to sub-dimensions

\begin{tabular}{lr}
\hline t- Test: Paired Two Samples for Means (p.V $=$ two-tail) \\
\hline Pronunciation & $\mathrm{t}(18)=-0.33,0.74>0.05$ \\
Syntax & $\mathrm{t}(18)=-2.45,0.02<0.05$ \\
Morphology & $\mathrm{t}(18)=-1.34,0.19>0.05$ \\
Aspect & $\mathrm{t}(18)=-1.34,0.19>0.05$ \\
Vocabulary & $\mathrm{t}(18)=-1.99,0.05<0.05$ \\
Functions & $\mathrm{t}(18)=-0.93,0.36>0.05$ \\
Negotiations & $\mathrm{t}(18)=-0.95,0.35>0.05$ \\
Discourse & $\mathrm{t}(18)=-0.71,0.48>0.05$
\end{tabular}

The p-value had to be equal to or below .05 to reject the null hypothesis. If $p$-values were higher than .05 , we would not reject our null hypothesis and consider that our approach did not improve oral performances in EFL among beginner-level learners at UBO. Our results showed Grammaring led to improvements in Form as was shown in section 4.1.1. But very effective progression was seen in Syntax. As regards Meaning, there was progression in Vocabulary which we as teachers in real-life may perceive as "too little improvement." Finally, for Use, there was no definite progression in any of its subdimensions in both the descriptive and inferential statistics.

\section{Conclusion}

In the previous sections, we reviewed the theoretical and practical considerations about Speaking and Grammaring to answer our research question. Firstly, we studied the relationship between Speaking and CLT, how this skill is studied in Chilean higher education, how this skill should be taught, and what kind of activities teachers should apply based on their teaching contexts (i.e., ESL or EFL). Moreover, in the speaking analysis, we noted that total immersion in English is useful to acquire oral skills; however, the type of interaction that is produced is more important than the amount of spoken English. Secondly, we covered the term Grammaring based on Larsen-Freeman's definition that provides a dynamic insight into language by means of its three dimensions: Form, Meaning and Use and their respective elements.

From a descriptive statistical view, the pre-test generally showed low scores in all the three dimensions of Grammaring in both the control and experimental groups. However, after receiving instruction in speaking activities, the experimental group who covered most of the macro dimensions, showed an average improvement in Form (Syntax and Morphology) and Meaning with diverse scores among participants. This peculiarity could be explored further in a qualitative analysis.

Additionally, the descriptive statistical analysis illustrated that by teaching through a Grammaring approach, learners had improvements in the majority of the dimensions of Form and Meaning in a shorter period than in the pragmatic aspects of Present Simple. So, it appears that developing the pragmatics aspects of language needs reinforcement through activities that develop discourse, negotiation and function.

Conversely, the inferential analysis, mainly the t-test, portrayed different results in the dimension of Form. The t-test showed improvements in only syntax and insignificant advancements in vocabulary. Consequently, activities that develop Meaning and/or Use may not be meaningful for beginner-level English learners.

Therefore, teaching Present Simple through the three dimensions of Grammaring can result in major developments in syntax, minor developments in the subdimension of lexical use, and insignificant developments in the three subdimensions of Use. Further research is needed to establish how Use can be improved and which factors would play a role in the development of this dimension.

Notably, our research was conducted over a three months' period. This timeframe suggests that time is a crucial factor, for researchers and teachers to take into consideration when helping learners to fully develop Grammaring and its' three macro aspects.

Finally, we highly recommend that further research into Grammaring should employ a qualitative approach to analyze the types of errors that are made in Present Simple and subsequently provide information on what activities may help overcome these errors based on learner's level of English.

\section{Acknowledgements}

We want to thank to all of the participants who were eager to support us and participated in all of stages that made this investigation possible. Also, we are very grateful for some colleagues, Eliza Enriquez and Fernanda Galvez from INACAP Institute. This research received specific grant from Bernardo O’Higgins University from Chile in particular from Research contestable funds. 


\section{References}

Astorga Cabezas, E. (2015). The relationship between listening proficiency and speaking improvement in higher education: Considerations in Assessing speaking and listening view. Higher Learning Research Communication Journal, 5(2), 34-36. https://doi.org/10.18870/hlrc.v5i2.236

Batstone, R., \& Ellis, R. (2009). Principled Grammar Teaching. System, 37, 194-204. https://doi.org/10.1016/j.system.2008.09.006

Bayu, J. (2015). Communicative Language Teaching. Changing Students' Speaking Skill. Premise Journal, 4, 1-14. https://doi.org/10.24127/pj.v4i1.277

Brown, H. (2004). Language Assessment: Principles and classroom practice. New York: White Plains: Pearson Longman.

Brown, H. (2006). Principles of language learning and teaching (5th ed.). White Plains, NY: Pearson Education.

Bygate, M. (1987). Speaking: The Cambridge guide to teaching English to speakers of other Language. Cambridge: Cambridge University Press.

Canale, M. (1983). From communicative competence to communicative language pedagogy. In J. E. Alatis (Ed.), Georgetown university round table on languages and linguistics: Language, communication, and social meaning (pp. 223-237). Washington, D. C.: Georgetown University Press.

Celce-Murcia, M., Dörnyei, Z., \& Thurrell, S. (1995). Communicative competence: A pedagogically motivated model with content specifications. Issues in Applied Linguistics, 6(2), 5-35. https://doi.org/10.5070/L462005216

Creswell, J. (2009). Research Designs: Qualitative, Quantitative and Mixed Methods Approaches. California: SAGE Publications Ltd.

Curtain, H., \& Dahlberg, H. (2004). Languages and Children: Making the Match, New Languages for Young learners. New York: Longman.

Cushing, S. (2002). Assessing writing. Cambridge, UK: Cambridge University Press.

Griffith, W., \& Lim, H.-Y. (2014). Introduction to Competency-based Language Teaching. MEXTESOL Journal, $1-9$.

Guskey, T. R. (2005). Mapping the Road to Proficiency. Educational Leadership, 63(3), 32-38.

Harmer, J. (1987). Teaching and Learning Grammar. London: Longman.

Higgs, T., \& Clifford, R. (1982). The push toward communication. In T. Higgs (Ed.), Curriculum, competence, and the foreign language teacher (pp. 51-79). Skokie, IL: National Textbook Co.

Hinkel, E. (2017). Prioritizing Grammar to Teach or Not to Teach: A Research Perspective. In E. Hinkel (Ed.), Handbook of Research in Second Language Teaching and Learning (pp. 369-383). New York: Routledge. https://doi.org/10.4324/9781315716893-27

Jones, P. (1996). Planning an oral language program. In Pauline Jones (Ed.), Talking to learn (pp. 12-26). Melbourne: PETA.

Kibbe, T. (2017). The History of Communicative Language Teaching ans its use in classroom. New York: Center for Faculty Excellence - United States Military Academy.

Krashen, S. (1988). Principles and Practice in Second Language Acquisition. Prentice-Hall International, 1987.

Larsen-Freeman, D. (2001). Teaching Language: From Grammar to Grammaring. Boston: Heinle \& Heinle.

Larsen-Freeman, D. (2003). Teaching from Grammar to Grammaring. Boston: Heinle Cengage Learning.

Larsen-Freeman, D. (2014). Teaching Grammar. In M. Celce-Murcia, D. M. Brinton \& M. A. Snow (Eds.), Teaching English as a Second or Foreign Language (4th ed., pp. 256-270). Boston: Heinle Cengage Learning.

Lightbown, P. M. (1998). The importance of timing on focus on form. In C. Doughty \& J. Williams (Eds.), Focus on form in classroom second language acquisition (pp. 177-196). Cambridge: Cambridge University Press.

Long, M. H. (1991). Focus on form: A design feature in language teaching methodology. In K. de Bot, R. Ginsberg \& C. Kramsch (Eds.), Foreign language research in cross-cultural perspective (pp. 39-52). Amsterdam: John Benjamins. https://doi.org/10.1075/sibil.2.07lon

Longcope, P. (2009). Differences between the EFL and the ESL Language Learning Context. Japanese Institutional Repositories Online, 303-320. 
Luoma, S. (2004). Assessing Speaking. Cambridge: Cambridge University Press. https://doi.org/10.1017/CBO9780511733017

Melgarejo, D. (2009). Assessing children's perceptions of writing in EFL based on the process approach. Colombian Applied Linguistics Journal, 12(1), 70-84. https://doi.org/10.14483/22487085.92

Mochida, A. (2002). What was the theoretical and empirical justification for the rise of communicative language teaching? Retrieved from https://www.geocities.jp/akiramochida33/clt.html

Nunan, D. (1989). Designing tasks for the communicative classroom. Cambridge: Cambridge University Press.

Nunan, D. (1998). Second Language Teaching and Learning. Heinle ELT.

Oxenden, C., Latham-Koenig, C., Hudson, J., Hamilton, G., \& Jay, D. (2009). New English File Beginner Teacher's Book. Oxford: Oxford University Press.

Oxenden, C., Latham-Koenig, C., Seligson, P., Clandfield, L., \& Target, F. (2004). New English File Elementary Teacher's Book. Oxford: Oxford University Press.

Pan, Y. C., \& Pan, Y. C. (2011). Conducting Speaking Tests for learners of English as a Foreign Language. The International Journal of Educational and Psychological Assessment, 83-84.

Prabhu. N. S. (1987). Second Language Pedagogy. Oxford: Oxford University Press.

Rao, Z. (2000). Chinese students' perceptions of communicative and non-communicative activities in the EFL classroom. System, 30, 85-105. https://doi.org/10.1016/S0346-251X(01)00050-1

Richard, Jack C., \& Renandya W. A. (2002). Methodology in language Teaching: An Anthology of Current practice. Cambridge: Cambridge University Press. https://doi.org/10.1017/CBO9780511667190

Richards, J., \& Rodgers, T. (2001). Approaches and Methods in Language Teaching. New York: Cambridge University Press. https://doi.org/10.1017/CBO9780511667305

Rickheit, Gert, \& Strohner, Hans. (2008). Handbook of Communication Competence. Berlin: Mouten de Gruyter. https://doi.org/10.1515/9783110199000

Swan, M. (2011). Grammar. In J. Simpson (Ed.), The Routledge Handbook of Applied Linguistics (pp. 557-570). Abingdon: Routledge.

Talley, P., \& Hui-ling, T. (1994). Implicit and Explicit Teaching of English Speaking in the EFL Classroom. International Journal of Humanities and Social Science, 38-46.

Thornbury, S. (2001). Uncovering Grammar. Oxford: MacMillan Heinemann.

UCLES. (2007). Key English Test Handbook for teachers. Cambridge: University of Cambridge ESOL Examinations.

UCLES. (2016). Cambridge English Preliminary Handbook for teachers. Cambridge: University of Cambridge Language Assessment.

Ur, P. (2011). Grammar Teaching: Research, Theory, and Practice. In E. Hinkel (Ed.), Handbook of Research in Second Language Teaching and Learning (pp. 507-522). New York: Routledge.

Wang, P. J. (2009). A study of teacher and student perceptions concerning grammar-translation method and communicative language teaching. Nanya Journal, 28, 135-152.

Williams, J. (1995). Focus on form in communicative language teaching: Research findings and the classroom teacher. TESOL Journal, 4(4), 12-16.

Wong, Ruth. (2008). Competency-based English Teaching and Learning: Investigating Pre-service teachers of Chinese's Learning Experience. Porta Linguarum, 9, 179-198.

$\mathrm{Wu}, \mathrm{W}$. (2008). Misunderstandings of Communicative Language Teaching. English Language Teaching, 1(1), 50-53. https://doi.org/10.5539/elt.v1n1p50

Yin, C., \& Barrea-Marlys, M. (2012). The Role of Grammar in Communicative Language Teaching: An exploration of second language Teachers' Perceptions and Classroom Practice. Electronic Journal of Foreign Language Teaching, 9(1), 61-75.

\section{Copyrights}

Copyright for this article is retained by the author(s), with first publication rights granted to the journal.

This is an open-access article distributed under the terms and conditions of the Creative Commons Attribution license (http://creativecommons.org/licenses/by/4.0/). 